\title{
Work stress and recovery measured by urinary catecholamines and cortisol excretion in long distance coach drivers
}

\author{
Judith K Sluiter, Allard J van der Beek, Monique H W Frings-Dresen
}

\begin{abstract}
Objectives-To evaluate coach drivers' work stress during work and in the course of recovery from work by measurement of urinary catecholamines and cortisol.

Methods-The urinary excretion rate of adrenaline, noradrenaline, and cortisol of 10 coach drivers was studied during a long distance trip of three days and two consecutive days off. Each driver was asked to provide seven urine samples on the working days and six urine samples on the days off. The second day off was considered as the baseline.

Results-An occupationally induced disturbance of the circadian rhythmicity was found for adrenaline and noradrenaline but not for cortisol. The mean excretion rates of adrenaline on the first working day and most samples on all working days were higher than the baseline. For both adrenaline and noradrenaline the mean excretion rates on the first day off were lower than the baseline. For cortisol, the mean excretion rate on all working days was higher than the baseline. A trend towards accumulation of cortisol excretion from the first working day to the third working day was found. A backward shift in peak concentrations was found for adrenaline and noradrenaline on the second working day, as was a forward shift in peak concentration of cortisol on both days off.
\end{abstract}

Conclusions-Long distance coach drivers showed occupationally induced reactivity in rates of urinary excretion of adrenaline, noradrenaline, and cortisol. After the outward journey the rates of excretion of catecholamines did not return to baseline values. The course of recovery in adrenaline excretion after the journey showed a new phenomenon, which has been called "fatigue debt". It is recommended that longer resting times in shuttle bus trips and fixed days off after these kind of trips should be planned. Extensive future research should be focused on the additional relations between fatigue debt and health complaints.

(Occup Environ Med 1998;55:407-413)

Keywords: recovery; catecholamines; cortisol

A recent review based on 32 studies $^{1}$ showed a high prevalence of various disorders in city bus drivers, psychological (fatigue, sleeping prob- lems, tension, and mental overload), gastrointestinal, and musculoskeletal (back and knees). These health complaints were found to be associated with work stress, caused by the combination of high demands, low control, and low support in the job. ${ }^{1}$ Neuroendocrine responses to stressors include reactions of the pituitary adrenocortical system and the sympathetic adrenomedullary system. The measurable physiological changes accompanying stress are increased excretion of cortisol and adrenaline..$^{1-3}$ The beneficial effects of appropriate adjustment to novel situations by heightened excretion of adrenaline and cortisol are assumed to turn into adverse effects on health if these levels are chronically increased or prolonged activity is asked for. ${ }^{2}$ Noradrenaline reactivity mainly takes place in physically demanding tasks and therefore provides additional information about task demands. ${ }^{45}$ Evaluations of work stress by means of excretion of catecholamines or cortisol during work have been performed in studies on city bus drivers, but also on lorry drivers. ${ }^{14-10}$

By contrast with city bus drivers, lorry drivers and coach drivers mostly perform long distance trips. These trips often exceed several 24 hour periods, which means that the task demands are high and the work continues during night hours. In their classic study, Mackie and Miller ${ }^{6}$ investigated 12 lorry drivers and six bus drivers during long trips. They concluded that due to circadian rhythmicity, excretion rates of adrenaline and noradrenaline were lower during the late night and early morning on irregularly scheduled trips when compared with the regularly scheduled trips mainly performed during daytime. Furthermore, a cumulative fatigue effect was found in combination with high adrenaline excretion during the final regular trip. Vivoli et al studied three long distance lorry drivers. Although individual differences were great, increases in excretion rates of adrenaline and noradrenaline were found in all subjects in the afternoon hours and in conditions like driving in fog. For cortisol, the normal circadian rhythm was found and no stress related increases were reported. Due to circadian rhythmicity, plasma secretion rates of cortisol are high in the early morning and low in the late evening. ${ }^{11-13}$ Circadian rhythmicity in adrenaline and noradrenaline show peak concentrations in the early afternoon. ${ }^{2-16}$

Reactivity in rates of excretion of catecholamines and cortisol during work are seen as normal and essential neuroendocrine responses to enable contextual coping. Recovery from work is the rate at which return to the 
baseline concentrations of these hormones takes place after work. When the subjects are unable to unwind completely, this is described in terms of a spillover of neuroendocrine activity. This spillover has been found in catecholamines ${ }^{45}$ but not in cortisol. Repeated insufficient recovery from work related fatigue is seen as the take off of a vicious circle in which extra effort has to be exerted at the beginning of every new working period to rebalance the suboptimal psychophysiological state, and to prevent performance breakdown. ${ }^{45}$ Time seems to be the crucial variable in recovering from occupationally exerted efforts. The question of whether repeated insufficient unwinding of catecholamine concentrations during the off work recovery period is responsible for the onset of long term health complaints, has often been raised lately. ${ }^{245}$ This same question should be raised and investigated for cortisol.

A questionnaire study of long distance lorry drivers ${ }^{14}$ showed that excessive sleep of $>14 \mathrm{~h}$ occurred after trips in $40 \%$ of drivers and usually more than two days were necessary for complete recovery after prolonged trips in $80 \%$ of drivers. Less attention has been paid to the course of recovery from work as measured by catecholamines and cortisol excretion. ${ }^{45}$ Hartley et $a l^{15}$ investigated three long distance lorry drivers - that is, one solo driver and one double crew. The solo driver showed a greater proportional increase over the journey in catecholamines than the double crew. Furthermore, it was suggested that between the start of the outward and the start of the return journey some recovery in catecholamines excretion took place. Finally, Kuiper et $a \bar{l}$ emphasised the role of recovery from work in their study on 28 lorry drivers. They showed the relation between increased sympathoadrenal activation after work and health problems: spillover of sympathoadrenal activation, as assessed by urinary excretion of adrenaline and noradrenaline, was positively related to self reported psychosomatic health complaints. Thus, the rate of return to baseline of catecholamine concentrations after work, equalling the subject's ability to unwind after stressful work, may be an important predictive factor for health in the long run.

Studies on work stress which evaluated the course of recovery over more days by measurements of catecholamines and cortisol have not been performed before. Because the work of coach drivers has characteristics - such as longer duration of trips, irregularity in working

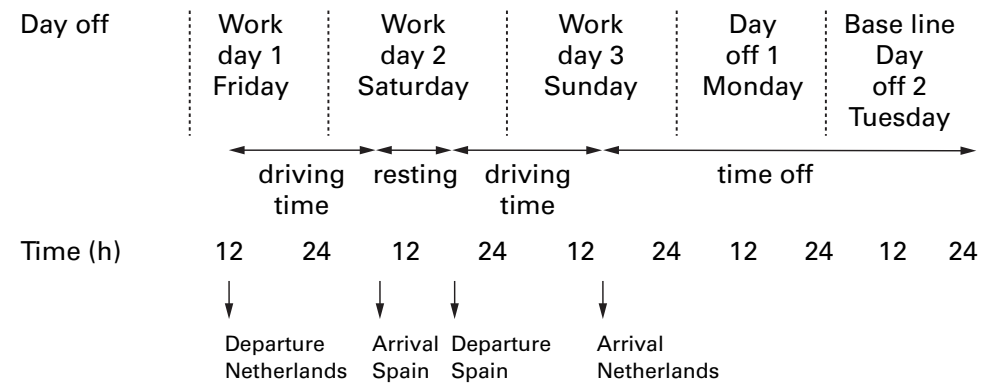

Figure 1 Overall timetable of a double crew's journey from The Netherlands to Spain. Driving and resting time and consecutive time off. hours, and longer distances that have to be covered, occupationally induced fatigue and the ensuing needs for recovery can be expected in coach drivers. The aim of this study was to evaluate work stress and corresponding recovery by means of urinary excreted adrenaline, noradrenaline, and cortisol. This was tested in long distance coach drivers.

\section{Methods}

SUBJECTS

Ten Dutch coach drivers, involved in five long distance shuttle trips from The Netherlands to Spain, were selected by random sampling from all coach companies in the private passenger sector. Conditions for subjects to be included were: (a) a minimum of one years experience in driving long distance shuttle trips, (b) knowledge of the route, and (c) one day off before the trip, and two days off after the trip. Informed consent was given by all subjects.

\section{DESCRIPTION OF JOURNEYS}

The routes from the south of The Netherlands, through Belgium, Luxembourg, and France, to Spain were identical for each driver. Data were collected within six weeks in October and November 1996. All trips had two drivers in each coach. Continuous observation of tasks and activities of both drivers took place by means of the observation system TRAC (task recording and analysis on computer). ${ }^{17}$ All details about road conditions (motorways, suburban roads, town roads, traffic jams) and visibility (clear, fog, rain, night) were noted in a diary. During the trip when producing urine samples, drivers were asked to self report with scales on subjectively experienced workload (from $0=$ no effort at all, 150=extremely strenuous), active-exhaustion (10 points scale), and relaxed-tense (10 points scale). Departures for Spain were on Friday around noon and arrival in Spain was on Saturday morning. Departures for The Netherlands were on the same Saturday in the early evening after a resting time during the afternoon, and arrival in The Netherlands was on Sunday around noon. Figure 1 shows a timetable of working days and days off.

\section{URINARY COLLECTION AND MEASUREMENTS}

Measurements of catecholamines and cortisol were performed during the daily work routine, during a resting period in Spain, and during two days off work after the trip to establish the recovery rates within each subject and baseline concentrations of catecholamines and cortisol. Thus, urine was collected during a consecutive period of five days equalling three working days, and two consecutive days off. The drivers were asked to collect all urine in this period and to provide samples around $0700,1100,1400$, 1700,2000 , and 2300 . Because the journeys covered two nights, the drivers were also asked to provide samples around 0400 on these nights. The drivers were asked to record the time of the last urination in the night before the journey. Because of the real life character of the study, it was decided not to restrict the drivers in behavioural habits. Obviously, data on consumption of coffee, tea, alcohol, and 
medicine during all five days were collected to be able to control for differences. Furthermore, it was asked whether emotional events - such as a quarrel or other traumatic incidents-had occurred. All times of urination were recorded and all samples were collected in different jars containing $0.7 \mathrm{~g}$ citric acid. After collection, jars were kept as cold as possible until further preparation started within 24 hours. After assessment of the volume per urine jar, $40 \mathrm{ml}$ was kept, of which $20 \mathrm{ml}$ was acidified with 0.1 $\mathrm{ml} 10 \mathrm{M} \mathrm{HCl}$. These $20 \mathrm{ml}$ samples were kept frozen $\left(-20^{\circ} \mathrm{C}\right)$ until analysis. The urinary catecholamine concentrations were determined from the acidified $20 \mathrm{ml}$ part by high performance liquid chromatography with fluorescence detection by the method of Boos et al. ${ }^{18}$ The urinary cortisol concentrations were determined from the unacidified $20 \mathrm{ml}$ part by high performance liquid chromatography on a $\mathrm{C}_{18}$ column with UV detection (240 nm).

DATA ANALYSIS AND STATISTICS

The urinary concentrations (ng. $\mathrm{ml}^{-1}$ ) were multiplied by the volume of the corresponding urine sample (ng). This amount was divided by the period between the urination of this sample and the previous urination, to obtain the mean excretion rate for that period (ng. $\left.\mathrm{min}^{-1}\right)$. All statistical analyses were performed with the SPSS Package for Windows. Firstly, the overall mean excretion rate each day was calculated for all five days. Differences between these overall means were tested by paired $t$ tests. Secondly, for each day a repeated measures analysis of variance (MANOVA; $F$ test) was performed to test whether there were diurnal differences. If so, differences per sample time between the three working days and first day off were compared with the second day off (baseline) by means of paired $t$ tests. To control for differences in coffee, tea, alcohol, and medicine intake between the five days, and for differences in relative duration of the performance of the main tasks between the five journeys, (MANOVA; $F$ test) was performed. In all analyses differences were accepted as significant at $p<0.05$. Because of sample size, marginal significancy is reported for $0.05<\mathrm{p}<0.10$.

\section{Results}

SUBJECTS

The 10 male subjects had a mean (SD) age of 47 (7) and had a mean (SD) driving experience on long distance shuttle coach trips of 11 (9) years. Although the absolute 24 hour levels of the consumption of coffee, nicotine, and alcohol were high (averaging 11 cups, 16 cigarettes, and four glasses a day, respectively), no differences (MANOVA, repeated measures) in consumption were found between the three working days and the first day off when compared with the baseline.

JOURNEY

The activities of the crews were broadly similar: travelling comparable routes on comparable days and times, loading and unloading, taking breaks according to the regulations governing driving hours, and taking resting time in Spain. No differences were found in relative duration of the main tasks performed between the five journeys (MANOVA; $F$ test). Mean (SD) journey time was 49 (3) hours with a mean (SD) driving time as the main task of 16.5 (2.5) hours and mean (SD) resting time at the destination in Spain of 8.5 (1.5) hours. During the resting time on the second working day, the drivers slept on average $5.4(0.9)$ hours during the day time. The total duration of the trip, and the time spent at the destination varied up to four hours between the five trips. No unusual weather or traffic conditions were noted.

\section{ADRENALINE}

Figure 2 shows the mean (SD) urinary excretion rates of adrenaline on the five

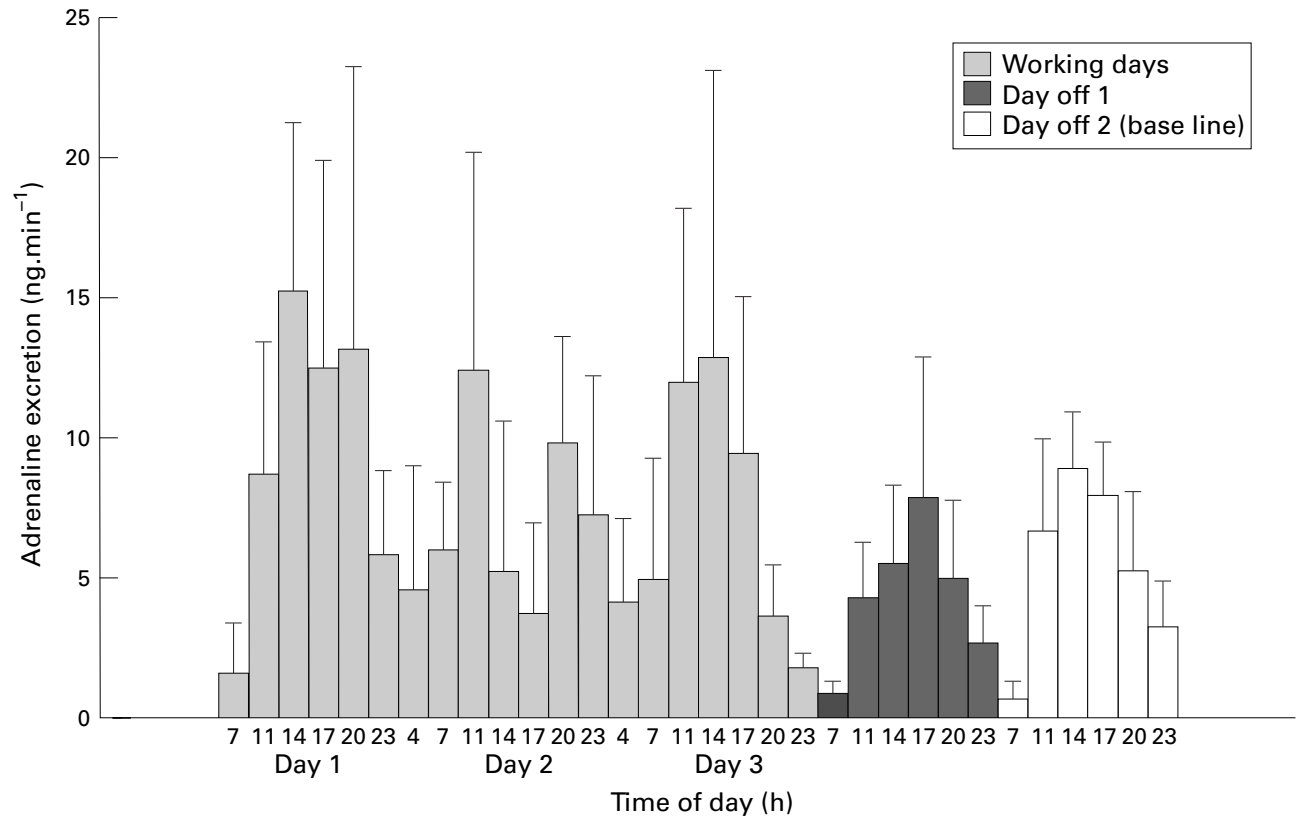

Figure 2 Adrenaline excretion rate $\left(n g . \mathrm{min}^{-1}\right)$; mean $(S D)$ a day and sample time $(n=10)$. 
consecutive days (appendix A1 shows the exact values). The overall mean excretion rate of adrenaline on the first working day was significantly higher than the overall excretion rate on the other four days $(p<0.01$ compared with the second working day and the first day off; $\mathrm{p}<0.05$ compared with the third working day and the second day off). The overall mean excretion rate of adrenaline on the first day off was significantly lower than the overall excretion rate on the other three days $(p<0.01$ compared with the first working day and the second day off; $p<0.05$ compared with the second and third working days). On all five days, a circadian rhythmicity was notable $(\mathrm{p}<0.05$ for all days). The peak concentration was reached around midday (sample $1400 ; 15.2,12.9$, and 8.9 ng. $\mathrm{min}^{-1}$ on the first and third working days and the second day off, respectively). On the second working day disturbance of the circadian rhythmicity was notable: the drivers slept between from around 1130 to 1630 and the peak concentration was reached before 1100 $\left(12.4 \mathrm{ng} \cdot \mathrm{min}^{-1}\right)$. On the first day off, the peak concentration was reached around tea time (17 00; 7.9 ng. $\left.\mathrm{min}^{-1}\right)$. Significant differences $(p<0.05)$ between the working days and the baseline concentration were found for the 14 00, 2000 , and 2300 sample on the first working day, for all samples on the second working day, and for the 0700,1100 , and 2300 samples on the third working day. Furthermore, marginal differences were found for the 1100 and 1700 sample on the first working day, and the 2000 sample on the third working day.

\section{NORADRENALINE}

Figure 3 shows the mean (SD) urinary excretion rates for noradrenaline on the five consecutive days (appendix A2 shows exact values). On all five days a circadian rhythmicity was notable ( $p<0.05$ for all days). The overall mean excretion rate of noradrenaline on the first working day was marginally significantly higher than the overall excretion rate on both days off. Peak concentration was reached around midday on the first and the second day off (14 00: 56.4 and 52.1 ng. $\mathrm{min}^{-1}$ respectively), and before 1100 on the second and the third working day (61.2 and $59.8 \mathrm{ng} \cdot \mathrm{min}^{-1}$, respectively). On the first working day, peak concentration was reached around tea time (17 00; 60.8 ng. $\mathrm{min}^{-1}$ ). Significant differences between working days and the baseline excretion rates were found for the first working day (07 00 and 2000$)$, the second working day (04 00,0700 , and 1400 ), and the third working day (04 00 and 07 00, all p<0.05). Compared with the baseline, a marginally significant difference was found for the 1700 sample on the second working day.

\section{CORTISOL}

Figure 4 shows the mean (SD) urinary excretion rates of cortisol on the five consecutive days (appendix A3 shows exact values). The overall mean excretion rate of cortisol on the first working day was marginally significantly higher than the overall excretion rates on both days off $(p=0.05)$. The overall mean excretion rate on the second and third working days were significantly higher than the overall excretion rate on the second day off $(p<0.01$ and $\mathrm{p}<0.05$, respectively). The overall mean excretion rate of cortisol on the first day off was significantly lower than the overall mean excretion rate on the second and third working day $(p<0.01)$. For all five days a circadian rhythmicity was found $(p<0.001)$. Peak concentration was reached in the early morning on the first, second, and third working days (07 00: 31.4, 51.2 and $55.8 \mathrm{ng} \cdot \mathrm{min}^{-1}$, respectively), and around 1100 on the first and second day off (30.9 and 32.2 ng. $\mathrm{min}^{-1}$, respectively). Compared with both days off, excretion rates early in the morning were significantly higher on the three working days $(0700: p<0.05)$. Marginally significant higher excretion rates were

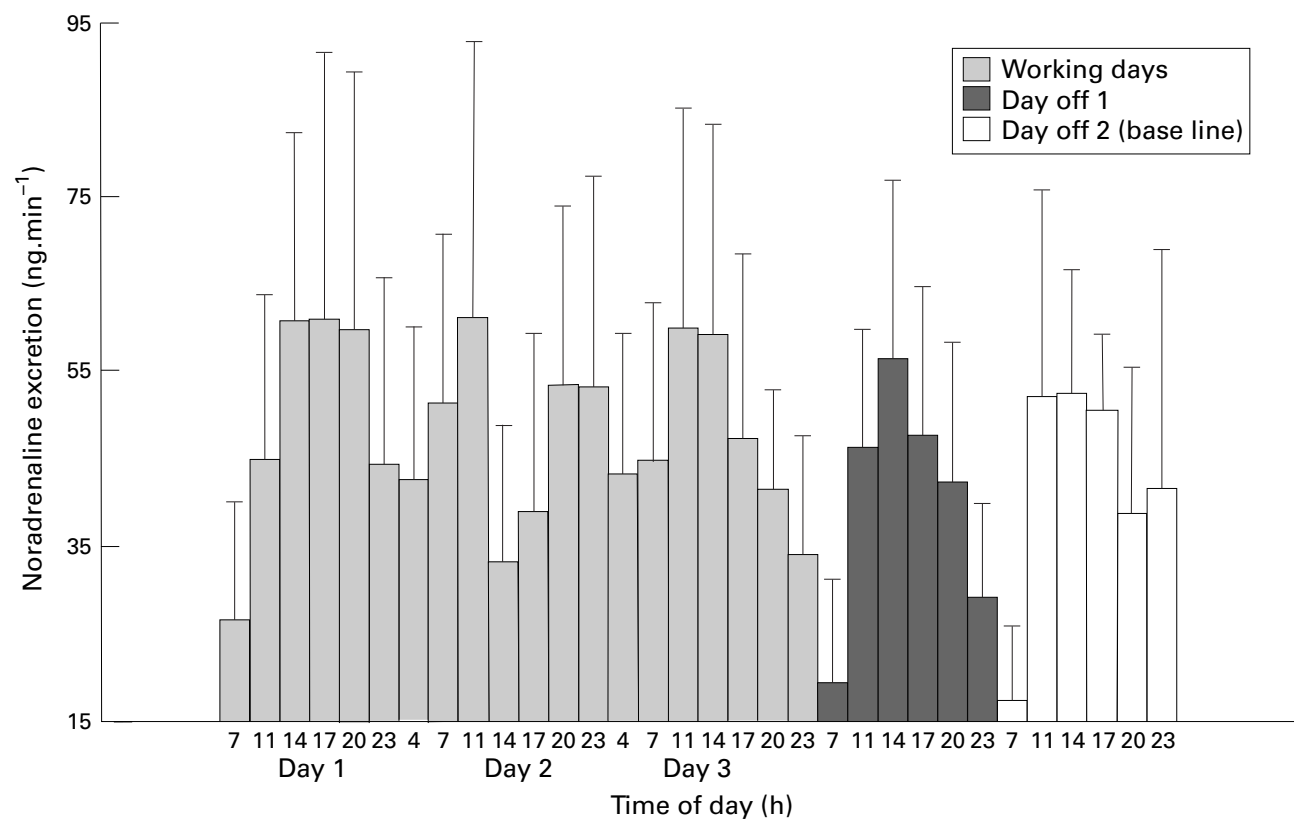

Figure 3 Noradrenaline excretion rate $\left(n g . \mathrm{min}^{-1}\right)$, mean $(S D)$ a day and sample time $(n=10)$. 
found in the 0700 samples of the second and third working days than on the first working day.

\section{SELF REPORTS}

On the third working day the drivers experienced significantly $(\mathrm{p}<0.05)$ more workload than on the first working day, and on the second working day they felt significantly $(p<0.05)$ less active than on the first working day. No differences between the days were found for the active-tension scales.

\section{Discussion}

The relation between catecholamines and cortisol, and their reactivity patterns in off work recovery periods remains unclear so far. In this study of 10 coach drivers, it was therefore decided to assess both urinary catecholamines and cortisol during work as well as after work to investigate the course of recovery. In accordance with most earlier studies, , $^{2-10} 13151619$ normal circadian rhythms were found for the excretion rates of adrenaline and noradrenaline in four out of five days, and absolute concentrations of adrenaline and noradrenaline were also comparable. ${ }^{458}$ Because subjects slept during the daytime on the second working day, the circadian rhythmicity was highly disturbed on this day. However, the cortisol concentrations on this day showed the same normal pattern as on the other days, which is in accordance with the finding that onset of adjustment of circadian rhythmicity in plasma secretion of cortisol takes place only after changes in daily sleeping habits of five to 10 days. ${ }^{11-13}$

Normally, peak concentrations in adrenaline and noradrenaline are present in the early afternoon. ${ }^{2-12141519}$ This was confirmed in the present study, except for the second working day, on which disturbance of the rhythm took place because of daytime sleeping. The peak concentration of the catecholamines on the second working day was found around 1100 during off work time, and, more importantly, it reached a value almost equal to that of the early afternoon on the other working days. Arrival in Spain (start of resting time) was in the early morning, thus recovery from work with accompanying relatively lower excretion rate would have been expected at 1100 . Furthermore, to be assured of sufficient hours of sleep, sleep onset of the drivers should start around 1000 . This suggests that at the registered level of activation, quality of sleep was not optimal.

Peak concentration in cortisol is normally reached in the early morning, ${ }^{11}{ }^{12}$ and sleep deprivation for one or two nights did not prevent the sharp rise of cortisol in the early morning hours described by Weitzman. ${ }^{13}$ However, in the present study peak concentration in cortisol on both days off was reached around 1100 by contrast with the earlier peaks on the working days. A hypothetical explanation for this finding is that the drivers needed prolonged sleep on their days off. Thus, physiologically there was no need to be ready for action earlier. This line of argument could also explain the slow start in adrenaline excretion on the first day off compared with baseline. This finding is in accordance with that of Milosevic. ${ }^{14}$ "Fatigue debt" is the term proposed here for this phenomenon-namely, that rates of excretion of adrenaline lag behind and remain at a sub-baseline concentration during a large part of the first day of recovering from work. It is unclear whether there is an additional relation between lack of recovery time and (development of) health complaints of workers. The number of subjects in this study did not allow assessment of this relation. More extensive studies are called for. It is hypothesised that starting work repeatedly in a state of fatigue debt requires extra exertion which in the long run could have adverse effects on health. Future longitudinal research should confirm this hypothesis. In a questionnaire study among 363 coach drivers ${ }^{20}$ subjective

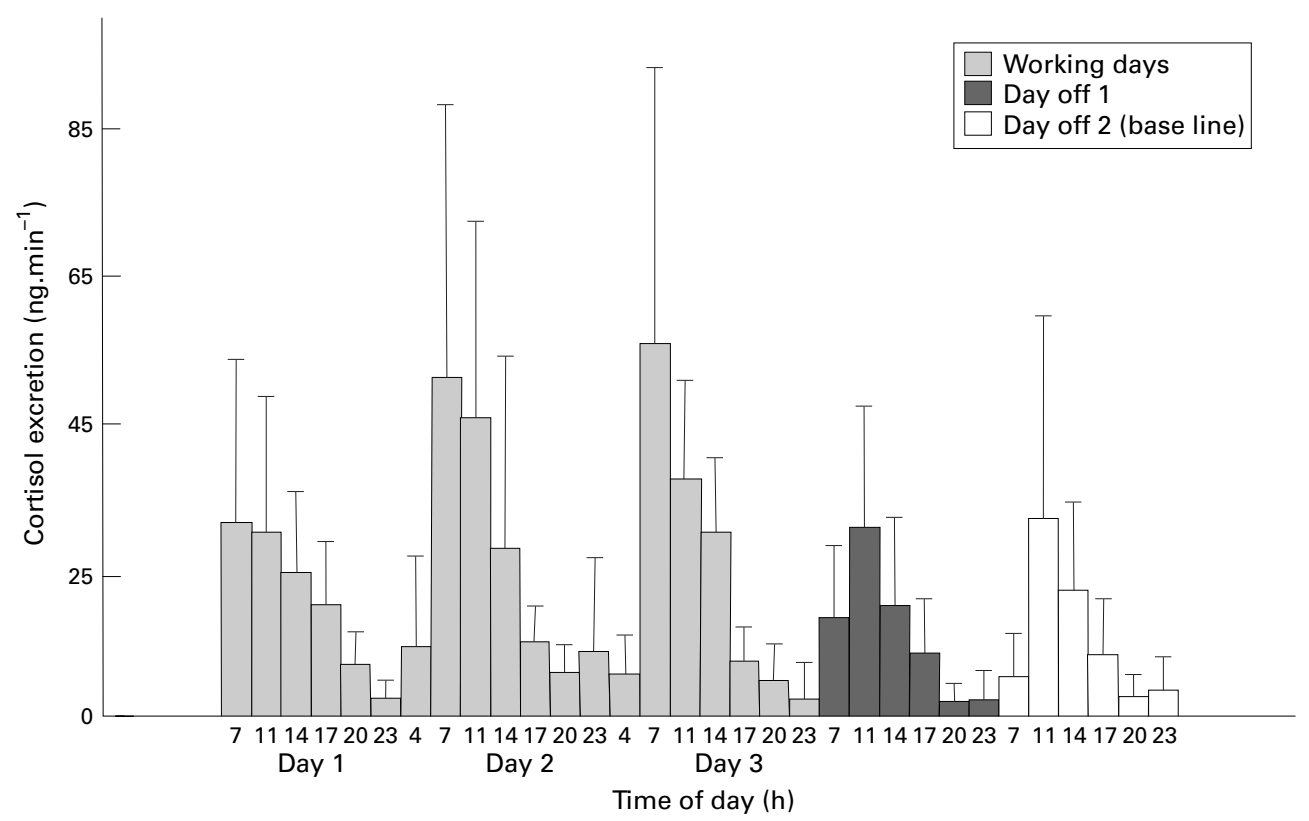

Figure 4 Cortisol excretion rate $\left(n g . \mathrm{min}^{-1}\right)$, mean $(S D)$ per day, and sample time in hours $(n=10)$. 
needs for recovery were positively related to complaints of general health, sleep quality, and emotional exhaustion.

The differences found in the overall mean rates of excretion of the catecholamines per day were in accordance with outcomes of some studies, ${ }^{6}{ }^{9}$ and different from another. ${ }^{15}$ During working days, these mean rates of excretion were higher than in leisure time. It is accepted that more noradrenaline reactivity than adrenaline reactivity takes place in physically demanding occupations ${ }^{45}$ and the reverse holds for mentally demanding occupations. ${ }^{2}$ Because driving can be seen as a mainly mentally demanding occupation, it was not surprising that fewer differences were found in noradrenaline than in adrenaline reactivity. Therefore, in this study noradrenaline was a useful control variable and indicated equal disturbances in circadian rhythmicity as did adrenaline. Although cortisol excretion is thought to occur in short term bursts when people meet stressful events, ${ }^{16}{ }^{21}$ the overall mean excretion of cortisol in this study was significantly higher on working days compared with baseline. Figure 4 shows that there seems to be an accumulation of excretion in cortisol from the first to the third working day, although the drivers slept and rested during the daytime of the second working day. Although not significantly, all excretion rates of the second working day remained higher than their baselines. Recovery of the observed accumulated excretion rates of cortisol took place after the journey.

The self reports indicated that although the resting time theoretically should have been sufficient to recover, more workload was experienced by the drivers during the return journey than during the outward journey. To get a natural picture in this real life study, no constraints were put on the normal behavioural habits of the subjects. However, the self reported use of stimulants did not differ between the days.

To evaluate recovery, the procedure of collection of urine on consecutive days, as outlined in the methods section, seems to be successful. This procedure is promising for investigation of short term effects from work such as spillover, ${ }^{4}$ but also effects in the course of recovery from work such as fatigue debt. Although Hartley et $a l^{15}$ also investigated long distance trips, recovery time between the outward and return journey was not taken into account. In the study of Mackie and Miller, ${ }^{6}$ urine was collected on six consecutive days, but again no recovery time was accounted for. The same goes for Vivoli et al. ${ }^{7}$ Extension of this study among other workers with the method outlined here, is therefore needed.

\section{Conclusion}

Coach drivers showed occupationally induced reactivity in rates of urinary excretion of adrenaline and noradrenaline, after control for stimulants. Rates of urinary excretion of cortisol increased during the three working days, regardless of resting time in between outward journey and return journey. The course of recovery, as measured on a consecutive day off, showed a fatigue debt in adrenaline excretion and similar reactions in cortisol excretion. During the resting time after the outward journey the rates of excretion of catecholamines did not return to baseline values, which seems to indicate incomplete recovery. We recommend that longer resting times on shuttle bus trips and at least one day off after these kind of trips are planned. Finally, in future research projects we recommend focusing on recovery from work as well as reactivity during work. This focus on recovery implies assessments of consecutive days in which more than one workshift and more than one day off work are included. It remains to be established whether adrenaline or cortisol is the best standard to measure recovery from work. Furthermore, more extensive research should be focused on the additional relations between fatigue debt, spillover, or incomplete recovery, and health complaints.

We thank Selma Bassie and Josien Coppoolse for their great help during data collection, Sijmen Kuiper for the assessment of catecholamines and cortisol samples, and Dr Ineke Sluiter for her textual contribution.

Appendix 1: Rate of adrenaline excretion $\left(n \cdot\right.$ min $\left.^{-1}\right)$, mean (SD) per day and sample time $(n=10)$

\begin{tabular}{|c|c|c|c|c|c|}
\hline & \multicolumn{5}{|c|}{ Rate of adrenaline excretion $\left(\right.$ ng. min $^{-1}$ ) } \\
\hline & $\begin{array}{l}\text { Work day } 1 \\
\text { mean (SD) }\end{array}$ & $\begin{array}{l}\text { Work day } 2 \\
\text { mean (SD) }\end{array}$ & $\begin{array}{l}\text { Work day } 3 \\
\text { mean (SD) }\end{array}$ & $\begin{array}{l}\text { Day off } 1 \\
\text { mean }(S D)\end{array}$ & $\begin{array}{l}\text { Day off } 2 \text { (base } \\
\text { line) mean (SD) }\end{array}$ \\
\hline \multicolumn{6}{|c|}{ Sample time $(\mathrm{h})$ : } \\
\hline 0400 & $-\quad(-)$ & $4.64(4.4)$ & $4.17(3.0)$ & $-(-)$ & $-\quad(-)$ \\
\hline 0700 & $1.62(1.8)$ & $6.05(2.4)$ & $5.01(4.3)$ & $0.93(0.5)$ & $0.80(0.6)$ \\
\hline 1100 & $8.72(4.7)$ & $12.41(7.8)$ & $12.03(6.2)$ & $4.36(2.0)$ & $6.74(3.3)$ \\
\hline 1400 & $15.24(6.0)$ & $5.27(5.4)$ & $12.93(10.2)$ & $5.58(2.8)$ & $8.94(2.0)$ \\
\hline 1700 & $12.52(7.4)$ & $3.78(3.2)$ & $9.46(5.6)$ & $7.94(5.0)$ & $7.99(1.9)$ \\
\hline 2000 & $13.16(10.1)$ & $9.83(3.8)$ & $3.75(1.8)$ & $5.05(2.8)$ & $5.34(2.8)$ \\
\hline 2300 & $5.86(3.0)$ & $7.32(4.9)$ & $1.83(0.6)$ & $2.76(1.3)$ & $3.37(1.6)$ \\
\hline
\end{tabular}


Appendix 2: Rate of noradrenaline excretion $\left(\mathrm{ng} \cdot \mathrm{min}^{-1}\right)$, mean (SD) per day and sample time (n=10)

\begin{tabular}{|c|c|c|c|c|c|}
\hline & \multicolumn{5}{|c|}{ Rate of noradrenaline excretion $\left(\right.$ ng. $\left.\mathrm{min}^{-1}\right)$} \\
\hline & $\begin{array}{l}\text { Work day } 1 \\
\text { mean }(S D)\end{array}$ & $\begin{array}{l}\text { Work day } 2 \\
\text { mean }(S D)\end{array}$ & $\begin{array}{l}\text { Work day } 3 \\
\text { mean (SD) }\end{array}$ & $\begin{array}{l}\text { Day off } 1 \\
\text { mean (SD) }\end{array}$ & $\begin{array}{l}\text { Day off } 2 \text { (base line) } \\
\text { mean (SD) }\end{array}$ \\
\hline \multicolumn{6}{|c|}{ Sample time (h): } \\
\hline 0400 & $-\quad(-)$ & $42.58(17.5)$ & $43.15(16.1)$ & $(-)$ & $(-)$ \\
\hline 0700 & $26.54(13.6)$ & $51.33(19.3)$ & $44.90(17.9)$ & $19.45(11.9)$ & $17.30(8.7)$ \\
\hline 1100 & $44.80(19.0)$ & $61.20(31.4)$ & $59.79(25.3)$ & $46.33(13.4)$ & $51.99(23.6)$ \\
\hline 1400 & $60.61(21.6)$ & $33.22(15.2)$ & $59.09(24.0)$ & $56.44(20.4)$ & $52.08(14.4)$ \\
\hline 1700 & $60.84(30.5)$ & $39.05(20.3)$ & $47.44(21.0)$ & $47.69(17.0)$ & $50.40(8.9)$ \\
\hline 2000 & $59.96(29.1)$ & $53.44(20.4)$ & $41.43(11.5)$ & $42.38(16.0)$ & $38.63(16.8)$ \\
\hline 2300 & $44.23(21.5)$ & $53.15(24.0)$ & $34.00(13.7)$ & $29.19(10.8)$ & $41.49(27.3)$ \\
\hline
\end{tabular}

Appendix 3: Rate of cortisol excretion $\left(\right.$ ng. $\left.\mathrm{min}^{-1}\right)$, mean (SD) per day and sample time $(\mathrm{n}=10)$

\begin{tabular}{|c|c|c|c|c|c|}
\hline & \multicolumn{5}{|c|}{ Rate of cortisol excretion (ng. min $^{-1}$ ) } \\
\hline & $\begin{array}{l}\text { Work day } 1 \\
\text { mean }(S D)\end{array}$ & $\begin{array}{l}\text { Work day } 2 \\
\text { mean }(S D)\end{array}$ & $\begin{array}{l}\text { Work day } 3 \\
\text { mean }(S D)\end{array}$ & $\begin{array}{l}\text { Day off } 1 \\
\text { mean }(S D)\end{array}$ & $\begin{array}{l}\text { Day off } 2 \text { (base } \\
\text { line) mean (SD) }\end{array}$ \\
\hline \multicolumn{6}{|c|}{ Sample time $(\mathrm{h})$ : } \\
\hline 0400 & $-\quad(-)$ & $14.44(12.7)$ & $10.99(5.2)$ & $(-)$ & $(-)$ \\
\hline 0700 & $31.42(22.4)$ & $51.16(37.2)$ & $55.82(37.4)$ & $18.60(9.8)$ & $10.60(5.9)$ \\
\hline 1100 & $30.14(18.6)$ & $45.69(26.6)$ & $37.21(13.4)$ & $30.89(16.4)$ & $32.17(27.3)$ \\
\hline 1400 & $24.58(11.0)$ & $28.06(26.0)$ & $30.13(10.3)$ & $20.14(12.4)$ & $22.25(12.0)$ \\
\hline 1700 & $20.20(9.0)$ & $15.21(5.2)$ & $12.54(4.8)$ & $13.80(7.4)$ & $13.47(7.7)$ \\
\hline 2000 & $11.94(5.0)$ & $11.11(4.0)$ & $10.13(5.1)$ & $7.16(2.6)$ & $7.62(3.3)$ \\
\hline 2300 & $7.51(2.8)$ & $13.64(13.0)$ & $7.41(5.2)$ & $7.21(4.4)$ & $8.56(4.8)$ \\
\hline
\end{tabular}

1 Kompier MAJ. Bus drivers: occupational stress and stress prevention. Geneva: International Labour Office 1996 (Working Paper. ONDI/T/WI.2/1996.)

2 Korunka C, Huemer KH, Litschauer B, et al. Working with new technologies: hormone excretion as an indicator for sustained arousal. A pilot study. Biol Psychol 1996;42:439-52.

3 Froberg J, Karlsson C-G, Levi L. Circadian variations in performance, psychological ratings, catecholamine excre-
tion and diuresis during prolonged sleep deprivation. International fournal of Psychobiology 1987;2:23-36.

4 Van der Beek AJ, Meijman TF, Frings-Dresen MHW, et al. Lorry drivers' work stress evaluated by catecholamines excreted in urine. Occup Environ Med 1995;52:464-9.

5 Kuiper JI, Van der Beek AJ, Meijman TF. Psychosomatic complaints and unwinding of sympathoadrenal activation after work. Stress Medicine 1998;14:7-12.

6 Mackie RR, Miller JC. Effects of hours of service, regularity of schedules and cargo loading on truck and bus driver fatigue. Goleta, California: Human Factors Research, 1978. (Technical report $1765-\mathrm{F}$.)

7 Vivoli G, Bergomi M, Rovesti S, et al. Biochemical and haemodynamic indicators of stress in truck drivers. Ergonomics 1993;36:1089-97.

8 Mulders HPG, Meijman TF, O'Hanlon JF, et al. Differential psychophysiological reactivity of city bus drivers. Ergonomics 1982;25:1003-11.

9 Jenner DA, Reynolds V, Harrison GA. Catecholamine excretion rates and occupation. Ergonomics 1980;23:23746.

10 Dimsdale JE, Moss J. Plasma catecholamines in stress and exercise. $尹 A M A$ 1980;243:340-3.

11 Conroy RTWL, Mills JN. Human circadian rhythms. London: Churchill, 1970;27-67.
12 Guyton AC. Textbook of medical physiology. Philadelphia: WB Sanders, 1980:952.

13 Weitzman ED. Circadian rhythms and episodic hormone secretion in man. Annu Rev Med 1976;27:225-43.

14 Milosevic S. Drivers' fatigue studies. Ergonomics 1997;40: 381-9.

15 Hartley LR, Arnold PK, Smythe G, et al. Indicators of fatigue in truck drivers. Applied Ergonomics 1994;25:14356 .

16 Akerstedt T, Levi L. Circadian rhythms in the secretion of cortisol, adrenaline and noradrenaline [editorial]. Eur $\mathcal{f}$ Clin Invest 1978; 8:57-8.

17 Frings-Dresen MHW, Kuijer PPFM. The TRAC-system: an observation method for analysing work demands at the workplace.Safety Science 1995;21:163-5.

18 Boos K-S, Wilmers B, Sauerbrey R, et al. Development and performance of an automated HPLC-analyzer for catecholamines. Chromatographia 1987;24:363-70.

19 Frankenhaeuser M, Lundberg U, Fredrikson M, et al. Stress on and off the job as related to sex and occupational status in white-collar workers. fournal of Organizational Behavior 1989;10:321-46.

20 Sluiter JK, Van der Beek AJ, Frings-Dresen MHW. Werkbelasting touring car chauffeurs. (Workload of coach drivers.) Amsterdam: Coronel Institute for Occupational and Environmental Health, University of Amsterdam, 1997. (Report No 97-03.)

21 Kirschbaum C, Gonzalez Bono E, Rohleder N, et al. Effects of fasting and glucose load on free cortisol responses to stress and nicotine. F Clin Endocrinol Metabol 1997;82: $1101-5$. 